\title{
Combined carbenicillin and gentamicin for prophylaxis of post-operative infection following major abdominal surgery
}

\author{
S. R. BLOOM* \\ M.A., M.B., B.Chir. \\ Mount Vernon Hospital, Northwood, Middlesex
}

\begin{abstract}
Summary
Bacteriological studies with carbenicillin and gentamicin individually and with the combination of these antibiotics suggest their effect to be additive in action and often synergistic. Of sixty-five organisms tested in vitro, the majority Gram-negative, forty-seven were resistant to ampicillin, thirtyseven to carbenicillin, twenty-four to gentamicin and only six to carbenicillin plus gentamicin.

Out of sixty-seven patients undergoing major abdominal surgery, thirty were randomly allocated to receive carbenicillin plus gentamicin postoperatively and of these one developed an infection. The other thirty-seven patients received either ampicillin or no antibiotic and nine developed infections.

The combined antibiotic regime seems suitable for prophylaxis for patients undergoing major abdominal surgery with a high risk of infection.
\end{abstract}

\section{Introduction}

The incidence of post-operative infection following abdominal surgery constitutes a serious hazard. In one large series infection, in all sites, occurred in over $30 \%$ of patients undergoing large bowel and prostatic surgery and in over $15 \%$ of those undergoing gastric and biliary surgery (Kippax \& Thomas, 1966). Other quoted figures for post-operative infection rates are similar (Public Health Survey on Wound Infection, 1960; Supplement to Ann. Surg., 1964; Nash \& Hugh, 1967). Unfortunately, many clinical trials of antibiotics used prophylactically have achieved disappointing results (Sanchez Ubeda, Fernard \& Rousselot, 1958; Taylor, 1960; Lancet, 1965). However, the antibiotics used were more effective against Gram-positive organisms than against Gram-negative organisms, which are now the commonest cause of infections (Finland, Jones \& Barnes, 1959; Quick \& Brogan, 1968).

The present study was undertaken to assess the value of combined carbenicillin and gentamicin, both of which are bactericidal antibiotics effective against

* Present address: House Physician, The Hammersmith Hospital, London, W.12.
Gram-negative organisms. Carbenicillin is an analogue of ampicillin but is more effective against Pseudomonas pyocyanea (Brumfitt, Percival \& Leigh, 1967; Bodey \& Terrell, 1968). Gentamicin is often effective against organisms resistant to the other aminoglycosides (Brayton \& Louria, 1964; Jao \& Jackson, 1964). Trials of these combined antibiotics were conducted both in vitro and in vivo.

\section{Materials and methods \\ Growth dynamics}

Three Gram-negative organisms selected at random were studied, an Escherichia coli, a Proteus and a Ps. pyocyanea. Each organism was grown in sterile tubes of Hartley's digest broth containing carbenicillin and gentamicin individually, at a concentration chosen to partially inhibit growth, and also in tubes with a combination of these antibiotics at the same and also at half the individual antibiotic concentrations. An inoculum from an overnight culture was added to each to produce approximately $10^{6}$ organisms $/ \mathrm{ml}$, and all the tubes for each organism were incubated simultaneously at $37^{\circ} \mathrm{C}$. Viable counts were made at $0,2,4,6$ and $24 \mathrm{hr}$ by the method of Miles \& Misra (1938).

\section{In vitro sensitivities}

Sixty-five fresh pathogenic organisms from different sources were provided by the routine bacteriological laboratory. Tubes of Hartley's digest broth were freshly prepared containing $4 \mu \mathrm{g} / \mathrm{ml}$ ampicillin, $20 \mu \mathrm{g} / \mathrm{ml}$ carbenicillin, $3 \cdot 2 \mu \mathrm{g} / \mathrm{ml}$ gentamicin and $20 \mu \mathrm{g} / \mathrm{ml}$ carbenicillin plus $3.2 \mu \mathrm{g} / \mathrm{ml}$ gentamicin. These antibiotic strengths were chosen as being exceeded by the serum levels for approximately $50 \%$ of the time following an intramuscular dosage of ampicillin $250 \mathrm{mg} 6$ hourly, carbenicillin 1 g 4 hourly (Acred et al., 1967) and gentamicin $80 \mathrm{mg} 8$ hourly (Gingell \& Waterworth, 1968). Serial dilution tubes of $1: 2,1: 4$ and $1: 8$ were also prepared for each antibiotic. An inoculum of an overnight culture, to produce approximately $10^{7}$ organisms $/ \mathrm{ml}$, was made into each of the tubes, which were incubated simultaneously for each 
organism and read for macroscopic turbidity at $18 \mathrm{hr}$.

\section{Clinical trials}

Seventy patients undergoing major abdominal surgery, both routine and emergency, were included in the trial over a period of 3 months. The operations are listed on Table 2. Patients under-. going minor abdominal surgery were excluded, e.g. any cystoscopic procedure, herniorrhaphy, laparotomy, clean appendicectomy and minor rectal conditions. At operation patients were divided into two groups. Group A contained patients likely to develop infections who required obligatory antibiotics. The others were allocated to Group B. Randomization within the groups was achieved by summing the age and hospital number, odd numbers forming the controls, and even numbers receiving carbenicillin and gentamicin. Control patients in Group A, the high risk group, received ampicillin $250 \mathrm{mg} 6$ hourly intravenously, intramuscularly or orally, whichever route was the most convenient. Control patients in Group B received no antibiotic. Patients in Group A and B given carbenicillin and gentamicin all received gentamicin $80 \mathrm{mg} 8$ hourly intramuscularly for 4 days only and carbenicillin $2 \mathrm{~g}$ 4 hourly for $24 \mathrm{hr}$, followed by $1 \mathrm{~g} 4$ hourly for a further 7 days intramuscularly, or intravenously when a drip was available. Antibiotics were begun within $2 \mathrm{hr}$ of operation. Any patient with a raised pre-operative blood urea, with penicillin sensitivity, or who had recently received a course of penicillin antibiotics was excluded from the trial. A close watch was kept for a poor urine output or any dizziness or deafness, but in fact no patient developed these contraindications to further treatment. Two patients on carbenicillin and gentamicin were $\frac{\varrho}{3}$ withdrawn from the trial when they developed $a$ 通 rash on the 1st and 4th post-operative days though $\stackrel{\varrho}{c}$ this rapidly faded on cessation of therapy. One $\Rightarrow$ patient, who was withdrawn from the control group, $\stackrel{0}{\rightarrow}$ had intestinal obstruction from disseminated carci- $\bar{Q}$ noma, became very shocked post-operatively and subsequently died. This left sixty-seven patients in $\frac{\bar{m}}{\frac{1}{2}}$ the trial. Post-operative assessment included daily $\mathbb{\Phi}$ examination for signs of infection, routine white counts on the 5th and 10th days, and a chest X-ray on the 5th day. Any wound area suspicious of $P$ infection was swabbed, although dressings were $\overrightarrow{\vec{\omega}}$ normally left until sutures were removed on the 10th day. Sputum, urine and stools were cultured whenever indicated.

\section{Results}

\section{Growth dynamics}

The growth curves of the three organisms are $\stackrel{\text { จे }}{\rightarrow}$ shown in Fig. 1. It is evident in each case that the 0 combination of carbenicillin and gentamicin, even at half concentration, was more effective than either 0 antibiotic alone. It is interesting that the combined $\mathbb{D}_{\overparen{D}}$ full concentration of carbenicillin and gentamicin still showed no detectable growth after a further 3 days incubation.

\section{In vitro sensitivities}

The results are shown in Table 1. Of the sixty-five organisms tested, forty-seven were resistant to the highest concentration of ampicillin used, including forty-two of the forty-eight Gram-negative organisms. With carbenicillin thirty-seven were resistant to the test concentrations including thirty of the
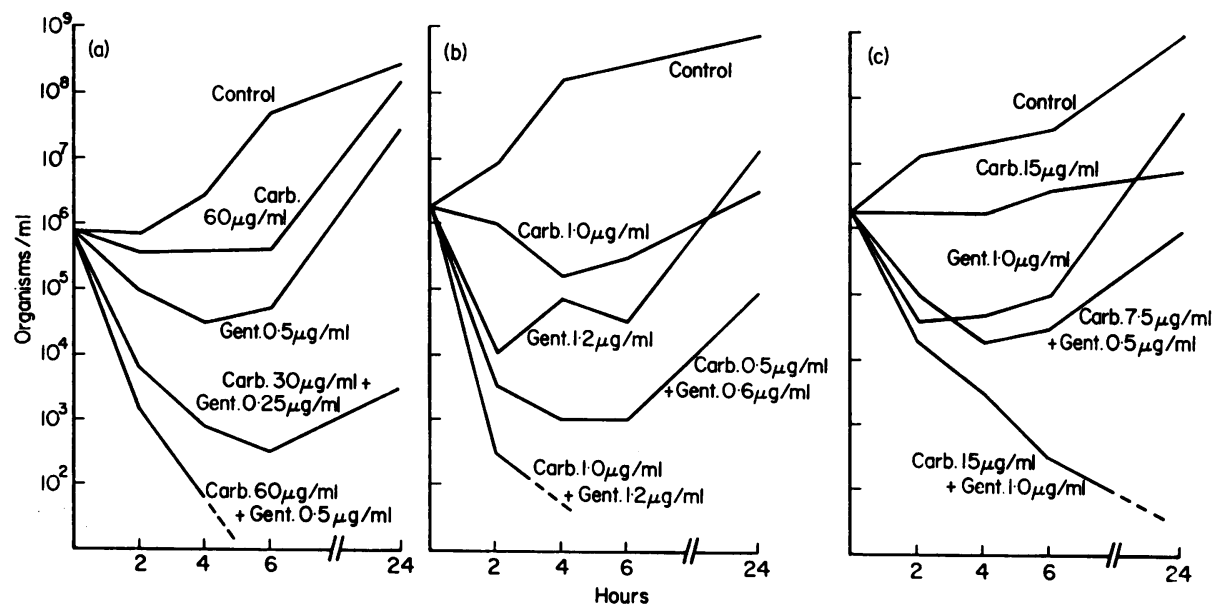

FIG. 1. Growth curves obtained with a Ps. pyocyanea (a), Proteus (b) and Esch. coli (c) against carbenicillin, gentamicin and the combination. 


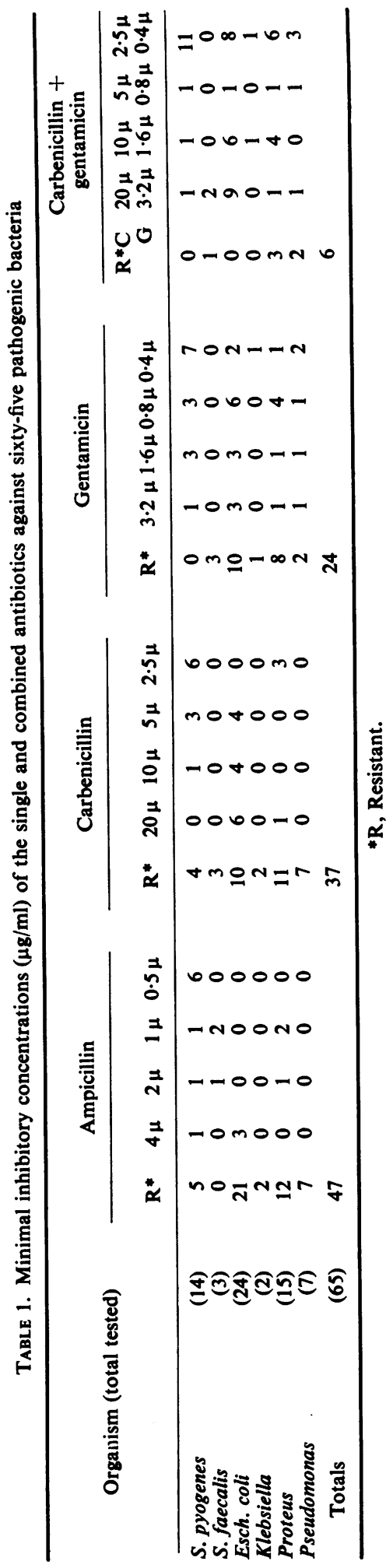


TABLE 2. Allocation of patients by numbers in the clinical trial

\begin{tabular}{|c|c|c|c|c|c|}
\hline \multirow{3}{*}{\multicolumn{2}{|c|}{$\begin{array}{c}\text { Operation } \\
\text { (No. of patients in parentheses) }\end{array}$}} & \multirow{2}{*}{\multicolumn{2}{|c|}{$\begin{array}{l}\text { Carbenicillin and } \\
\text { gentamicin }\end{array}$}} & \multicolumn{2}{|c|}{ Control } \\
\hline & & & & \multirow{2}{*}{$\underset{\text { A }}{\text { Ampicillin }}$} & \multirow{2}{*}{$\underset{\text { No antibiotic }}{\text { No }}$} \\
\hline & & A & B & & \\
\hline Thoraco-abdominal procedure & (4) & \multirow[t]{3}{*}{13,56} & & \multicolumn{2}{|l|}{$18^{*}, 47$} \\
\hline Vagotomy & (7) & & $4,8,51,62$ & \multirow{6}{*}{$9,46,54$} & \multirow{6}{*}{$\begin{array}{l}20,33,45 \\
44,60,61 \\
3,29,32,48,50 \\
23,28,53 \\
24,63 \\
49\end{array}$} \\
\hline Gastrectomy & (6) & & $11,16,35$ & & \\
\hline Cholecystectomy & (12) & \multirow[t]{2}{*}{37} & $5,40,64$ & & \\
\hline Bypass operations for cancer & (3) & & & & \\
\hline Division adhesions & (3) & & 14 & & \\
\hline Sigmoid myotomy & (2) & \multicolumn{2}{|l|}{10} & & \\
\hline Excision colon or rectum & (10) & $\begin{array}{l}10,17,41, \\
52,55\end{array}$ & 65 & $12,57,58$ & 25 \\
\hline Abdomino-perineal excision & (2) & 30 & & \multirow{3}{*}{$\begin{array}{l}36 \\
2,19,22,39\end{array}$} & \\
\hline Peritonitis & (8) & 43,67 & 31 & & 42 \\
\hline Prostatectomy & (6) & & $15,38,66$ & & $21,26,34$ \\
\hline Gynaecological & (4) & 1 & 6 & 27,59 & \\
\hline
\end{tabular}

*Figures in bold type indicate cases that developed an infection.

forty-eight Gram-negative organisms. In the case of gentamicin twenty-four were resistant to the test concentrations, but only six were resistant to carbenicillin plus gentamicin. Thus there were fiftynine organisms inhibited by the combined carbenicillin and gentamicin, and twenty-five of these were more sensitive to the combination than to either antibiotic individually, thereby suggesting the possibility of synergism. Of the thirty-four organisms not showing synergy, eighteen were sensitive to the lowest concentration of one of the antibioties so that synergy could not be detected by this method. There was no apparent case of antagonism.

\section{Clinical trial}

The results of the clinical trial are shown in Table 2. Thirty patients received carbenicillin and gentamicin (average age 58, range 29-82), twelve were in Group A and eighteen in Group B. Thirtyseven patients were controls (average age 56, range 25-86), fifteen in Group A received ampicillin and twenty-two in Group B received no antibiotic. In the patients treated with combined carbenicillin and gentamicin only one post-operative infection occurred $(3 \%)$. In the controls nine patients developed infections $(24 \%)$. Four of these patients had received ampicillin $(27 \%)$ and five had received no prophylactic antibiotic $(23 \%)$. This difference between patients receiving carbenicillin and gentamicin and the mixed control group is significant $(P<0.02)$. Details of patients' infections are given in Table 3 (average age 59, range 37-86).

Case 7 on carbenicillin and gentamicin became pyrexial 9 days after a sigmoid myotomy with a palpable rectal mass; this settled on conservative treatment. Case 18 developed a staphylococcal
TABLE 3. Details of infections in clinical trial

\begin{tabular}{lcc}
\hline \multicolumn{1}{c}{ Type of infection } & $\begin{array}{c}\text { Carbenicillin } \\
\text { and gentamicin }\end{array}$ & Controls \\
\hline Bronchitis & 25,26 \\
Pneumonia & 18 \\
Wound infection & 7 & $25,36,42,44,59$ \\
Pelvic abscess & 19 \\
Urinary infection & & 21,26 \\
\hline
\end{tabular}

pneumonia with high fever following oesophago jejunostomy for gastric carcinoma. Case 19 burst a sigmoid diverticulum and developed a pelvic abscess in spite of defunctioning colostomy and drainage. Case 21 developed an Esch. coli urinary infection 7 days after a prostatectomy and required 4 pints of blood for secondary haemorrhage. Case 25 developed a purulent bronchitis and a heavy wound discharge growing identical coliforms. Case 26 had a pyrexia of $102^{\circ} \mathrm{F}$ on the 7th day with a purulent sputum and an Esch. coli urinary infection. Cases 36, 42, 44 and 59 all developed wound discharge, pyrexia and positive swabs growing two Strep. pyogenes, a Strep. faecalis and a Proteus.

\section{Discussion}

The synergy of penicillins and aminoglycosides is well recognized in the traditional benzylpenicillin and streptomycin combination. Studies have shown ampicillin and gentamicin to be synergistic against Proteus spp. (Bulger \& Kirby, 1963) and methicillin and kanamycin against $S$. aureus (Bulger, 1967a, b). Therefore, it was reasonable to predict synergy with carbenicillin and gentamicin and in fact this was demonstrated in some organisms in each group tested. Indeed five out of fifteen Proteus spp. were sensitive only to the combined antibiotics in the 
test concentrations. The growth-curves demonstrate the combination of carbenicillin and gentamicin to be bactericidal at a concentration where the individual antibiotics were only bacteriostatic. In no case was antagonism between the two antibiotics seen. Thus the additive effect and wide spectrum of activity of this combination of antibiotics is exceptionally powerful in situations where a mixed Gram-negative infection occurs. $S$. faecalis, however, is not particularly sensitive to either antibiotic, and for this organism ampicillin is a better choice.

In the present clinical study carbenicillin and gentamicin proved to be effective in the prevention of post-operative infection in patients particularly at risk. The antibiotic regime was mostly administered intramuscularly and was well tolerated except by a few of the thinner patients. This had the advantage of avoiding bowel disturbances. Carbenicillin was given in $0.5 \%$ lignocaine to avoid pain on injection. Gentamicin used in the present dosage for 4 days is very unlikely to cause eighth nerve damage, its only significant toxic effect, provided that renal function is not impaired (Darrell \& Waterworth, 1967; Brit. med. J., 1967).

The value of routine antibiotic prophylaxis after surgery is still contested. A large survey covering several hospitals showed that post-operative infection was more common in those patients who had received prophylactic antibiotics. However, the study was retrospective and antibiotics were given principally to the patients at particular risk of infection (Supplement to Ann. Surg., 1964). A prospective study using penicillin and streptomycin also failed to show significant benefit (Sanchez Ubeda et al., 1958). However, several subsequent prospective studies showed a considerable decrease in infection (Ketcham et al., 1962; Nash \& Hugh, 1967; Collins, Darke \& Knowelden, 1968). These differences of opinion may be explained by the particular antibiotics employed. Many organisms likely to be contaminants following major abdominal surgery will be insensitive to the older antibiotics, for example $P$. pyocyanea and some strains of Proteus spp. and Esch. coli. Now that new antibiotics are available which are more effective against these organisms the position requires re-examination. Certainly there is a theoretical advantage in preventing the multiplication of bacteria in the first few post-operative days. In this period, before healing is well advanced, haematomas, drains, catheters and the likelihood of chest complications present unusual opportunities for bacterial invasion.

Unfortunately these two antibiotics are costly and their use carries a possibility of penicillin hypersensitivity or ototoxicity. This powerful combination should, therefore, be limited to a short fixed post-operative course and used in those patients where infection would otherwise be frequent and carry risk. The present study clearly demonstrates the value of the combination of carbenicillin and gentamicin in this context.

\section{Acknowledgments}

I would like to express my gratitude to $\mathrm{Mr} \mathrm{A}$. Elton and Mr A. Shorter, whose patients were studied in this trial, for their advice and encouragement and to Dr G. W. S. Andrews who generously allowed me the facilities of the pathology laboratory. Beecham Research Laboratories kindly supplied the carbenicillin (Pyopen) and Roussel Laboratories Ltd the gentamicin (Cidomycin Injectable).

\section{References}

Acred, P., Brown, D.M., Knudsen, E.T., Rolinson, G.N. \& Sutherland, R. (1967) New semi-synthetic penicillin active against Pseudomonas pyocyanea. Nature (Lond.), 215, 25.

Bodey, G.P. \& Terrell, L.M. (1968) In vitro activity of carbenicillin against Gram-negative bacilli. J. Bact. 95, 1587.

Brit. med. J. (1967) Reports on gentamicin. 1, 522.

Brayton, R.G. \& Louria, D.B. (1964) Gentamicin in Gram-negative urinary and pulmonary infections. Arch intern. Med. 114, 205.

Brumfitt, W., Percival, A. \& Leigh, D.A. (1967) Clinical and laboratory studies with carbenicillin. Lancet, $\mathbf{i}, 1289$.

BUlger, R.J. \& KIRBY, W.M.M. (1963) Gentamicin and ampicillin: synergism with other antibiotics. Amer. J. med. Sci. 246, 717.

BULGER, R.J. (1967a) In-vitro activity of cephalothin-kanamycin and methicillin-kanamycin combinations against methicillin resistant Staph. aureus. Lancet, i, 17.

Bulger, R.J. (1967b) Antibiotic combination in staphylococcal infections. Brit. med. J. 4, 805.

Collins, C.D., Darke, C.S. \& KNOWElden, J. (1968) Chest complications after upper abdominal surgery: their anticipation and prevention. Brit. med. J. 1, 401.

Darrell, J.H. \& WATERWORTH, P.M. (1967) Dosage of gentamicin for pseudomonas infections. Brit. med. $J$. 1, 535.

Finland, M., Jones, W.F. \& Barnes, M.W. (1959) Occurrence of serious bacterial infections since introduction of antibacterial agents. J. Amer. med. Ass. 170, 2188.

Gingell, J.C. \& WATERWorth, P.M. (1968) Dose of gentamicin in patients with normal renal function and renal impairment. Brit. med. J. 2, 19.

JAO, R.L. \& JACKSON, G.G. (1964) Gentamicin sulfate, new antibiotic against Gram-negative bacilli. J. Amer. med. Ass. 189, 817.

Ketcham, A.S., Block, J.H., Crawford, D.T., Lieberman, J.E. \& SMITH, R.R. (1962) The role of prophylactic antibiotic therapy in control of staphylococcal infections following cancer surgery. Surg. Gynec. Obstet. 114, 345.

Kippax, P.W. \& Thomas, E.T. (1966) Surgical wound sepsis in a general hospital. Lancet, ii, 1297.

Lancet (1965) Postoperative wound infection. i, 639.

Miles, A.A. \& MisRa, S.S. (1938) J. Hyg., Camb. 38, 732.

Nash, A.G. \& Hugh, T.B. (1967) Topical ampicillin and wound infection in colon surgery. Brit. med. J. 1, 471.

A Report of the Public Health laboratory Service (1960) Incidence of surgical wound infection in England and Wales. Lancet, ii, 659. 
Quick, C.A. \& BrogaN, T.D. (1968) Gram-negative rods and surgical wound infection. Lancet, i, 1163.

Sanchez Ubeda R., Fernand, E. \& Rousselot, L.M. (1958)

Complication rate in general surgical cases: the value of penicillin and streptomycin. New Engl. J. Med. 259, 1045.
Supplement on Post Operative Wound Infections (1964) Ann. Surg. 160, 332.

TAYLOR, G.W. (1960) Preventive use of antibiotics in surgery. Brit. med. Bull. 16, 51. 